\title{
Multi-sectoral approaches to preventing sexual assault and domestic violence: A collective force to stop the violence
}

Population Council

Follow this and additional works at: https://knowledgecommons.popcouncil.org/departments_sbsr-rh

Part of the Demography, Population, and Ecology Commons, Domestic and Intimate Partner Violence Commons, Family, Life Course, and Society Commons, Gender and Sexuality Commons, International Public Health Commons, Medicine and Health Commons, and the Women's Health Commons How does access to this work benefit you? Let us know!

\section{Recommended Citation}

"Multi-sectoral approaches to preventing sexual assault and domestic violence: A collective force to stop the violence." Johannesburg: Population Council, 2009. 




\section{ACKNOWLEDGEIMENTS}

"The Multi-Sectoral Approaches to Preventing Sexual Assault and Domestic Violence Symposium" which took place from 6 - 7 May 2009 in Gauteng, was jointly hosted by Population Council and AED-UGM, and funded by USAID's South Africa Mission through the President's Emergency Plan for AIDS Relief (PEPFAR).

The co-ordinators extend special thanks to the following people for their contributions to the symposium:

Professor Rachel Jewkes, Director, Gender and Health Research Unit of the Medical Research Council (MRC) of South Africa and Secretary, Sexual Violence Research Initiative (SVRI) for chairing the symposium and for providing valuable input to the programme.

We are grateful and indebted to the presenters who shared insightful and expert views on the strategies for the development of a collective force to stop the violence.

We also thank Ms Jacqueline Conley, Dr Saiqa Mullick, Ms Mantshi Teffo-Menziwa and Ms Leonie Selvan for their work in compiling and producing this report. 


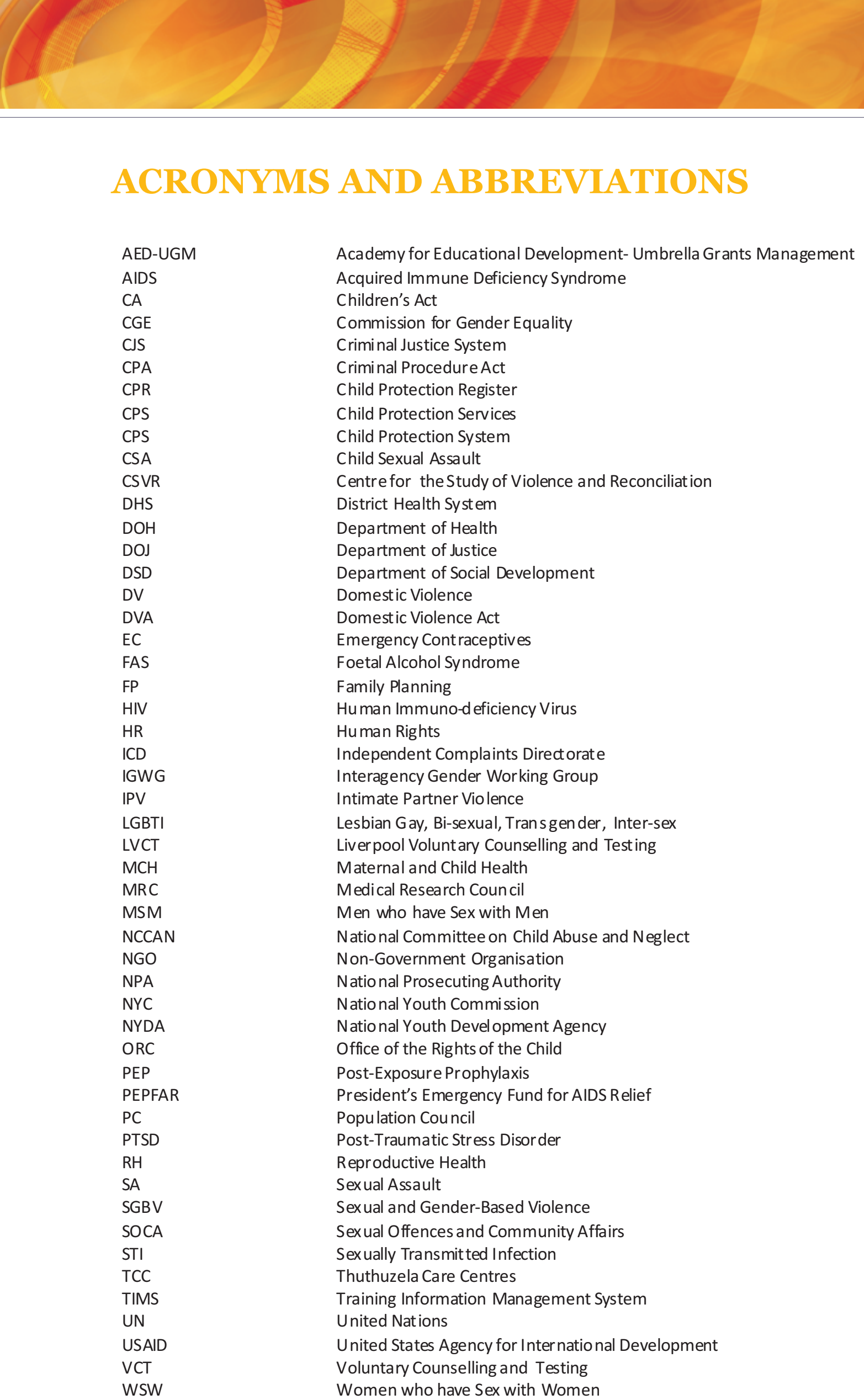




\section{TABLE OF CONTENTS}

Executive summary

$\begin{array}{lr}\text { 1. Introduction } & 4\end{array}$

$\begin{array}{ll}\text { 2. Gender-based violence and HIV } & 7\end{array}$

$\begin{array}{llr}\text { 3. } & \text { Addressing the risks } & 8\end{array}$

$\begin{array}{ll}\text { 3.1. } & \text { Male norms and gender equality }\end{array}$

$\begin{array}{ll}\text { 3.2. Youth, unemployment and poverty } & 9\end{array}$

$\begin{array}{ll}\text { 3.3. Alcohol and drug abuse } & 10\end{array}$

$\begin{array}{ll}\text { 3.4. Strengthened policing and enforcement } & 11\end{array}$

$\begin{array}{ll}\text { 3.5. Child abuse prevalence } & 13\end{array}$

$\begin{array}{ll}\text { 3.6. Sexual orientation and violence } & 16\end{array}$

$\begin{array}{lll}\text { 3.7. } & \text { Responses from prevention partners and Government } & 18\end{array}$

$\begin{array}{lr}\text { 4. Conclusion } & 20\end{array}$

$\begin{array}{lr}\text { 5. Appendices } & 21\end{array}$ 
The Multi-Sectoral Approaches to Preventing Sexual Assault and Domestic Violence Symposium jointly hosted by the Population Council and AED-UGM in May 2009, aimed to:

a. Increase awareness of sexual assault and domestic violence and its relationship to HIV and AIDS among decision-makers;

b. Promote evidence-based programming for practitioners;

c. Advocate for increased preventative measures and service delivery around SGBV in the public and private sectors;

d. Facilitate networking, strengthen and develop partnerships and create opportunities for ongoing collaboration between key stakeholders; and

e. Inspire a co-ordinated plan of action for prevention that supports the government's 365-day plan ${ }^{1}$ of action.

South Africa has some of the highest SGBV figures in the world. This is a violation of human rights of women and girls but is also a major cause of mortality and morbidity. In addition, SGBV is a key driver of the HIV epidemic for women. Existing male norms also serve to fuel the SGBV and HIV epidemics.

\section{Key findings of the symposium and recommendations on addressing the risks}

\section{Male norms and gender equality}

Solid policies are needed to engage men and boys, together with a clear strategic plan to accelerate change. We need to focus on issues compounding women's vulnerabilities to men's violence such as marriage regimes and maintenance, the Firearms Control Act and liquor laws. Several recommendations were identified, requiring that male norms be addressed and changed and that women become empowered and men educated by programmes on women's rights and human rights.

\section{Poverty and inequality}

Poverty and inequality are inseparably linked to all other social dynamics that underpin the problem of violence in South Africa. In addition, the constructions of masculinity which are predicated on gender hierarchy and idealise toughness and risk-taking are a key driver of gender-based violence. Research also shows that income inequality and unemployment are more consistent correlates of homicide than any other indicator. (Jewkes et al, 2008.)
Recommendations include job creation, recreational facilities, and involvement of youth in programme development.

\section{Alcohol and drug abuse}

South Africa has one of the highest per capita rates of alcohol consumption in the world. Alcohol leads to violence and aggression due to its psychopharmacological effects and links have been made between social and cultural attitudes, expectations and norms around alcohol which lead to violence. Recommendations are to create innovative ways to reduce supply and demand, and to reduce the overall availability and appeal of alcohol, especially to the youth.

\section{Strengthened policing and enforcement}

The police service is mandated to prevent, combat and investigate crime in order to maintain public order. They are to protect and secure the inhabitants of South Africa and their property, and they are there to uphold and enforce the law. However, the police and courts are not fairing well in this respect and many perpetrators are not prosecuted. The Sexual Offences and Community Affairs (SOCA) Unit of the National Prosecuting Authority (NPA) was established in October 1999 to eradicate all forms of gender-based violence against women and children.

The focus of the authorities should be to achieve justice and not merely crime control. Recommendations include information sharing between police, courts, prosecutors, shelters and social workers about gun ownership and threats with a gun.

\section{Protecting children from abuse and strengthening parenting}

The health consequences of child sexual abuse are well documented and lead to alcohol abuse, depression, HIV and further violent behaviour.

Children are confronted with several problems regarding their abuse, namely their response to the abuse (eg fear of being blamed for the rape), limited access to support services, and limitations of the Child Protection Services. Recommendations include additional resources and victimfriendly institutions, as well as a Child Protection Plan against child exploitation.

\footnotetext{
${ }^{1}$ The 365-day national action plan to end gender violence is a comprehensive and concerted plan for ending gender violence with measurable targets and indicators to which South Africans from all walks of life, in all spheres of government and at all levels of society can contribute.
} 


\section{Sexual orientation and violence}

There are many contradictions in South Africa related to gender and gender-based violence particularly with regard to lesbian, gay, bi-sexual, transgender and inter-sex (LGBTI) individuals. Whereas the Universal Declaration of Human Rights protects everyone from violent acts, LGBTI are subjected to horrific violence and even murder. Recommendations include training to debunk myths and stereotypes of gender, gender identity and sexual practices to lessen homophobia and increase tolerance.

\section{Responses from health partners and government}

Numerous opportunities exist for the health sector to provide care for SGBV survivors. Based on the number of people attending health facilities, health workers are often the first point of contact. A package of comprehensive sexual assault care by healthcare workers for rape victims needs to be implemented.

Recommendations include the empowerment of vulnerable communities. There is no blueprint of sexual assault service, however the model used must be adaptable to local settings, must be evidence-based and encourage inter-sectoral collaboration.

\section{Challenges for women and children regarding sexual assault}

When women report cases of rape to the police in South Africa they often become victims of secondary trauma because they are interrogated. Instead of feeling helped by those in authority, women feel further traumatized and helpless. Many rape cases that do make it to court end up being thrown out because of a lack of evidence. Due to this, many perpetrators go free. Local models strengthening links with the justice system exist.

\section{Conclusion}

Effective prevention of SGBV requires a comprehensive cross-sectoral approach with buy-in and political support at all levels of government. No single strategy alone will be effective. At present, there is insufficient co-ordination and monitoring of implementation of the national 365-day plan. There has also been limited engagement with civil society and oversight mechanisms like the Commission for Gender Equality (CGE) and Independent Complaints Directorate (ICD) face challenges. For any prevention interventions to work, civil society must work closely with government and increase its capacity to engage in policy, advocacy and community mobilisation. Similarly, public sector capacity must be strengthened to monitor and implement the national 365-day plan. Lastly, the involvement of traditional and religious leaders cannot be overlooked.

While specific recommendations have been made per sector there are general recommendations which apply across-the board and which will require cross-sectoral collaboration and commitment. This includes reducing poverty, ensuring stricter gun control, and finding men from civil society and positions of power who are role models.

It is hoped that the findings presented at the symposium will inspire stakeholders across all sectors to join forces to formulate a plan of action; that the symposium will guide advocacy and inform future interventions and research needs towards comprehensive HIV prevention in South Africa. 


\section{INTRODUCTION}

\section{Background}

Sexual and gender-based violence (SGBV) is endemic in communities around the world, cutting across class, race, age, religion and national boundaries.

SGBV is defined as, "Any act of gender-based violence that results in, or is likely to result in physical, sexual, or psychological harm or suffering for women, including threats of such acts, coercion, or arbitrary deprivation of liberty, whether occurring in public or private life."- United Nations General Assembly 1993.

The impact of SGBV resonates in all areas of health and social programming: survivors of sexual violence experience increased rates of morbidity and mortality, and violence has been shown to exacerbate HIV transmission, among other health conditions (IGWG of USAID, 2006).

While women and girls are the most visible survivors of sexual violence, they are far from being the only ones who suffer it. Children of both sexes constitute a large proportion of abuse survivors, and adult men and the handicapped are minority groups who are also affected but often neglected in research and interventions.

\section{A substantial number of African women are abused by their partners (2008 DHS data)}

\author{
Few countries have a higher proportion of \\ abuse than South Africa-Zambia has the most \\ physical abuse while Uganda has the highest \\ rates of sexual and emotional abuse.
}

South Africa has some of the highest SGBV figures in the world. This is a violation of human rights of women and girls but is also a major cause of mortality and morbidity. In addition, SGBV is a key driver of the HIV epidemic for women. Existing male norms also serve to fuel the SGBV and HIV epidemics.

Thus, in May 2009, in an effort to highlight the state of SGBV in South Africa, the Population Council and AEDUGM, funded by PEPFAR, co-hosted a symposium on MultiSectoral Approaches to Preventing Sexual Assault and Domestic Violence. The theme: A Collective Force to Stop the Violence.

\section{SGBV is a public health issue}

Fatal outcomes

- Femicide

- Suicide

- AIDS-related mortality

- Maternal mortality

\section{Non-fatal outcomes}

\begin{tabular}{|c|c|c|}
\hline Physical & Sexual and reproductive & $\begin{array}{l}\text { Psychological and } \\
\text { behavioural }\end{array}$ \\
\hline $\begin{array}{ll}\text { - } & \text { Fractures } \\
\text { - } & \text { syronic pain } \\
\text { - } & \text { Fybromes } \\
\text { - } & \text { Permanent disability } \\
\text { - } & \text { Gastro-intestinal } \\
& \text { disorders }\end{array}$ & $\begin{array}{l}\text { - Sexually-transmitted } \\
\text { infections, including HIV } \\
\text { - Urinary tract infections } \\
\text { - Unwanted pregnancy } \\
\text { - } \text { Pregnancy } \\
\text { complications } \\
\text { - Vaginal bleeding } \\
\text { - Traumatic gynaecologic } \\
\text { - } \text { fistula } \\
\text { - Chsafe abortion } \\
\text { Chronic pelvic pain }\end{array}$ & $\begin{array}{l}\text { - Depression and anxiety } \\
\text { - Eating and sleep } \\
\text { disorders } \\
\text { - Drug and alcohol abuse } \\
\text { - Poor self-esteem } \\
\text { - Post-traumatic stress } \\
\text { - disorder } \\
\text { - Self harm }\end{array}$ \\
\hline
\end{tabular}


Women who have been raped or have children who have been raped face many challenges:

- Are not believed by their families that the rape occurred, whether by a family member or not.

- Lose friends.

- Endure discrimination and stigmatisation.

- Husbands leave them.

- Lack love and support.

- Face threats, bribery and manipulation from perpetrators.

- End up in and stay in abusive relationships.

- Are faced with raising HIV-positive children who were infected by rape.

Often children who have been raped survive but are left feeling unloved and without support, protection or any guidance, making it easy for them to develop behavioural problems.

\section{"SGBV is a key driver of the} HIV epidemic for women. Existing male norms also serve to fuel the SGBV and HIV epidemics."

\section{RAPE AND INTIMATE PARTNER}

\section{VIOLENCE IN SOUTH AFRICA}

- A woman is killed every six hours by a husband or boyfriend in South Africa.

- Violence is the second leading cause of death after HIV.

- Close to 55000 rapes were reported to the police in South Africa between 2005 and 2006

- Only one in nine rapes is reported.

- Forty percent of rape cases reported are children $-15 \%$ of those are under 12 years.

- One in five women disclosed in research that they had been forced into sex by an intimate partner.

- Men who rape are more likely to have HIV.

- Men abused in childhood are twice as likely to abuse alcohol.

- Ten percent of men disclosed that they had been forced into sex by a man.

- Girls exposed to sexual abuse in childhood are more likely to be physically and sexually abused as adults.

- Boys who experienced abuse and were abused in childhood increase their risk of perpetrating violence, especially rape in adulthood.

- Women who have experienced physical or sexual intimate partner violence (IPV) are more likely to have HIV.

- Rape impacts on the mental health of rape survivors, increasing their long-term risk of contracting HIV. It also alters women's sense of self and makes them more likely to abuse substances. 


\section{GENDER-BASED VIOLENCE AND HIV}

Gender-based violence is increasingly recognised as a key factor in the HIV epidemic while sexual violence is often considered the key source of the increased risk. There is compelling evidence that women who are abused and men who abuse are more likely to have HIV. Women who have experienced physical/sexual intimate partner violence are more likely to have HIV (Dunkle K et al, 2004). Men who have perpetrated physical or sexual violence are more than twice as likely to have HIV (adjusted OR 2.23) and 73\% of men who will rape do so by the age of 20 . (Jewkes $\mathrm{R}$ et al, 2008).

There is evidence to support both direct and indirect pathways through which gender-based violence increases the risk of HIV. As a result of these mechanisms, young women between 15 and 26 years of age were $64 \%$ more likely to acquire HIV over two years of follow up. (Jewkes $\mathrm{R}$ et al, 2008).
Men who have perpetrated more than one episode of physical IPV are more likely to:

- have 20+ partners ever

- engage in any transactional sex

- have sex with a prostitute

- have high levels of alcohol in the past year

- rape

- use condoms inconsistently

- be or to have been sexually violent and exhibit a range of other risk factors.

\section{Hypothesised pathways from gender-based violence}

\section{Gender-based violence}

\section{to increased HIV-positivity in women}

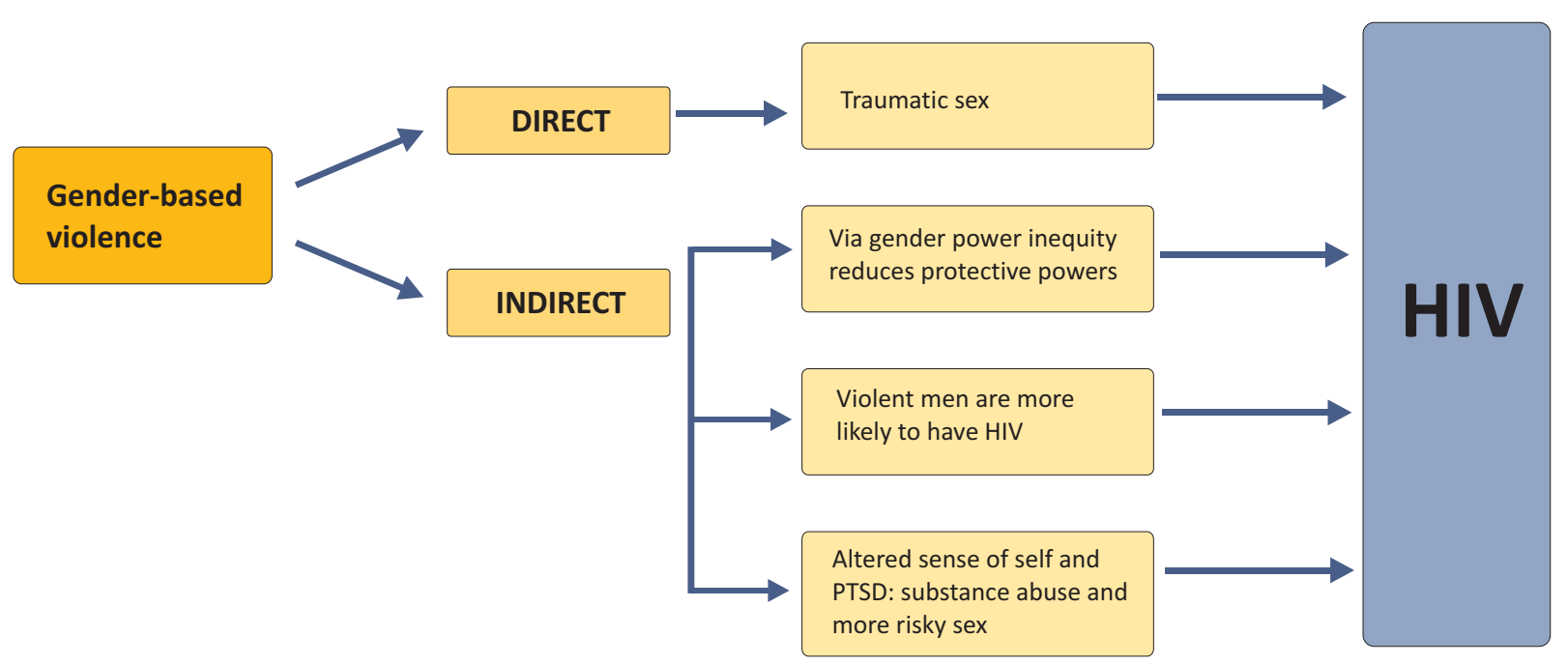




\subsection{Youth, unemployment and poverty}

While population growth in South Africa has slowed overall, there continues to be rapid growth amongst the youth and adults, with youth comprising $36 \%$ of the population. While today's youth have attained higher levels of education than previous generations, there is a mismatch between labour demand and supply. There is also a marked difference in unemployment rates between youth and non-youth.

Poverty and inequality are inseparably linked to all other social dynamics that underpin the problem of violence in South Africa. Research also shows that income inequality and unemployment are more consistent correlates of homicide than any other indicator.

\subsubsection{Causes of unemployment}

- Rapid labour force growth coupled with 'sedate' employment growth.

- Lack of funding to complete education.

- Lack of skills.

- Experience trap (ie people cannot get jobs because they have no experience, but no one will employ them and give them an opportunity to gain experience).

- Fields of study (choices are not driven by economic considerations in many instances).

- Employer perceptions (regarding quality of education, etc).

- Barriers to job search activity, barriers to selfemployment.

\subsubsection{Consequences of unemployment}

- Unemployment results in poverty and accompanying social ills:

- Permanent loss of production to economy.

- Erosion of skills over time.

- Lowered return on public and private investment in education.

- Increased burden on income-earners and grant recipients.

- Lowered self-esteem and depression.

- Increased likelihood of involvement in criminal activity.

\subsubsection{Challenges faced by youth}

Youth continue to face the transition from being a dependent to a provider with competition for scarce resources. Youth continue to grapple with understanding their sexuality, their bodies and maintaining a positive selfimage. Their sexual debut will need to be consensual and not coerced by a partner or peer and they will have to learn about sexual rights and responsibilities and respect for human rights. Culture (gender roles, patriarchy, and sex as taboo), values (class, money, power), transactional sex, early marriages, secrecy, family structures (absent parents, orphans and vulnerable children) and exposure to violence are all significant factors that are linked to SGBV.

\subsubsection{Recommendations}

\section{Job creation}

- Exposing school children to the work environment by taking them to visit the parent/guardian's workplace.

- Business opportunity with ongoing support (business skills/training, forum to discuss challenges and progress).

- Getting children involved in community services.

\section{Recreational facilities}

- Activities accommodating children of different ages.

- Involvement of the Department of Sports and Recreation.

- Have role models/mentors to help youth to understand the long-term effects of alcohol.

- Parents participating at children's sports events.

\section{Involvement of youth}

- Youth forums to form part of existing community forums.

- Including youth in meetings to allow them to articulate their needs and be part of the solution.

- Allowing youth to form part of the decision-making processes.

- Youth-friendly services, eg at police stations and health facilities youth need to feel their needs are addressed.

- Getting parents involved in their children's life through open communication about sex, drugs, school, friends and by parents showing an interest in technology without policing - mxit, TV games, etc

- Re-evaluate values that support individualism and which have eroded family structures and ubuntu and promote common good.

- Strengthened families and parenting reduces children's vulnerability and prevents SGBV. 


\subsection{Alcohol and drug abuse}

South Africa has one of the highest per capita rates of alcohol consumption in the world. Drinking is entrenched in society and the alcoholic beverage and advertising industries are a significant threat to efforts to address alcohol abuse.

\section{Some facts about alcohol}

\section{$21 \%$ of adult males and $7 \%$ of adult females show symptoms of alcohol problems. \\ - One quarter of South Africans drink excessively over weekends. \\ 29\% of males in grade 8 to 11 report past month binge drinking (18\% for females). \\ - Many South Africans drink up to 17 litres of alcohol per year. \\ - A review of 20 plus studies in Africa showed that drinkers are $57 \%$ more likely to be HIV- positive than non-drinkers. \\ - South Africa has the highest recorded levels of Foetal Alcohol Syndrome (FAS) in the world.}

\subsubsection{Links between alcohol use and violence}

- Alcohol leads to violence (aggression) due to its psychopharmacological effects.

- Individuals predisposed to heavy drinking are also predisposed to violence.

- Drinking predisposes people to engage in violent acts.

- Social and cultural attitudes, expectations and norms leads to violence (eg expectancies - alcohol leads to aggression; alcohol used for "Dutch courage" to engage in violent acts).

- A combination of the above factors (Graham et al, 1998).

\subsubsection{Recommendations}

- Reduce supply and demand.

- Increase taxes on all alcohol products.

- Drunk-driving counter measures (eg zero alcohol for drivers; random blood testing).

- More recreational facilities - alternative ways of socialising - to reduce alcohol use.

- Liquor regulations and policies to sell alcohol responsibly with stiff fines if they are contravened.

- Increase the availability of quality alcohol treatment services (DOH) and early intervention.

- Product restrictions (eg those appealing to minors such as coolers).

- Increase restrictions on advertising alcohol (eg billboards, sponsorships, no radio/TV adverts where youth are exposed).

- Increase counter-advertisements.

- Community mobilisation around alcohol abuse (eg push for early closing of problematic outlets).

- Active surveillance of alcohol outlets like shebeens (law enforcement - fines, revoke licenses, etc).

- Effective school-based prevention programmes such as:

- Prohibiting alcohol on school premises

- Reinforcing security around the school yard/ premises

- Adequate security guards

- Spontaneous spot checks (body and bags) 


\subsection{Strengthened policing and enforcement}

The police service is mandated to prevent, combat and investigate crime in order to maintain public order. They are to protect and secure the inhabitants of South Africa and their property, and they are there to uphold and enforce the law.

The role of legal interventions in a society is to provide protection or recourse in the event of a crime; to provide a powerful form of social sanction; and to spell out what is right and wrong and shape social norms.

However, the police and courts are not faring too well. (Vetten, L). The diagram illustrates the attrition of rape cases through the criminal justice system (CJS) in Gauteng from research involving 2068 rape cases reported in Gauteng in 2003 (TLAC, MRC, CSVR).

The study showed that only $17 \%$ of reported cases made it to trial and almost one quarter withdrew. In only $6.2 \%$ of all reported rape cases was the perpetrator convicted. The majority of cases are not reported.

In South Africa at present crime control is driving policing not justice - and the value of legal interventions is being undermined and denied to many. A good deal of attrition is unnecessary and avoidable; it is simply the result of an inadequate and ineffective system.

\section{Where cases fall out of the process}

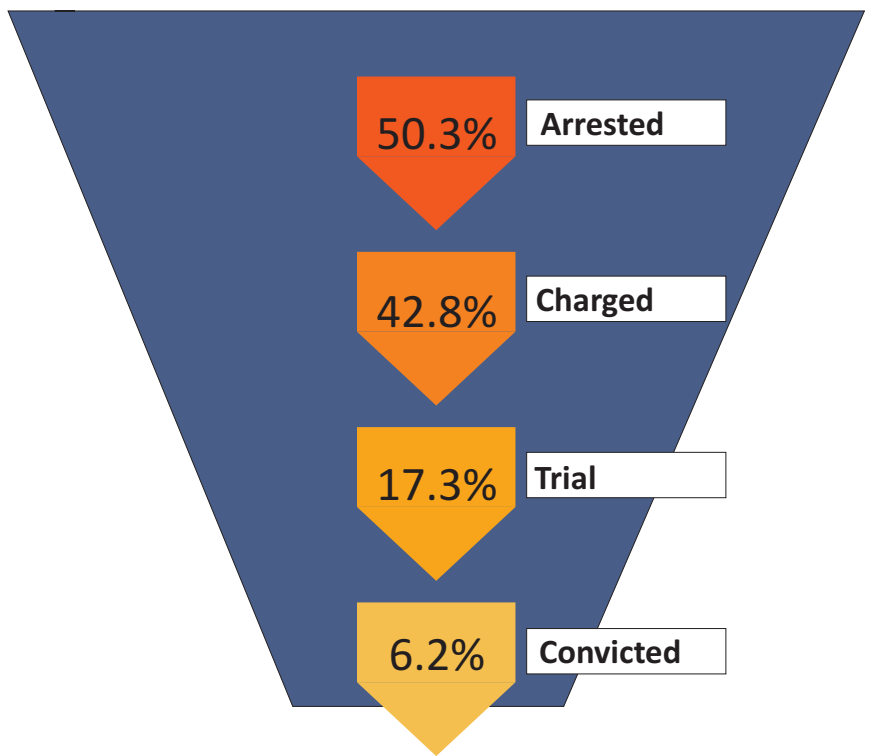

The justice system faces many challenges. Not only is there a lack of knowledge about legislation, procedures and crimes on the part of health providers and police. There is also a shortage of health and legal services in rural areas. The legal and health services should ideally be available 24 hours a day. Furthermore, there is a significant pro-gun lobby in South Africa. Domestic violence (DV) is underreported, and DV with guns is likely to be even less reported for fear of retaliation. The police often fail to remove a gun when responding to a DV call.

\subsubsection{Challenges}

- Services are not available 24 hours a day and suburbanrural access is poor.

- The contact details of victims and witnesses are often not documented.

- Matters are sometimes informally resolved between families.

- When women report cases of rape to the police in South Africa they often become victims of secondary trauma because they are now interrogated and asked the following questions: Did you receive money for the rape? What were you wearing?

- This is further exacerbated in court (if the case goes to trial) by defence attorneys who often ask embarrassing personal questions about the victim and magistrates who tell them that they asked for it. Instead of feeling helped by those in authority and who are expected to assist them, women feel further traumatized and helpless. 


\subsubsection{Responding to the challenges - the SOCA, NPA}

\section{Firearm involvement in rape and domestic violence}

- In South Africa, every 24 hours, a woman is shot by her intimate partner, killing her.

- The ownership of a legal firearm is one of the main risk factors in the murder of intimate female partners.

- Women are three times more at risk of being killed by an intimate partner when a gun is in the home.

- The perpetrator is usually a spouse or partner, often with a prior record of domestic abuse.

- $80 \%$ of multiple family killings involve guns - where the man kills family members and then himself.

- A gun in the home is much more likely to be used to intimidate or physically injure family members than be used against an outside intruder.

- Four out of five guns used in DV in South Africa are legal guns.

- For every woman killed or physically injured by firearms, many more are threatened.

The Sexual Offences and Community Affairs (SOCA) Unit of the National Prosecuting Authority (NPA) was established in October 1999 to eradicate all forms of gender-based violence against women and children. The unit is made up of four sections: Sexual Offenses; Domestic Offenses; Violence Maintenance; and Child Justice. Its vision is that there be justice and security for women and children by protecting their dignity and freedom from violence and abuse.

The SOCA Unit has initiated several interventions to combat domestic violence:

- Capacity building around the police, prosecutors and traditional leaders was identified as a strategic intervention to eradicate of all forms of gender-based violence.

- An integrated domestic violence manual that is SAQA accredited was developed and adapted to produce the train the trainer programme

- The outcome of Project Ndabezitha initiated by the SOCA unit was accredited trainers, facilitators and assessors from the National and Provincial Houses of Traditional Leaders. These included 80 traditional leaders and prosecutors.

\subsubsection{Recommendations}

- A large proportion of attrition is avoidable therefore the system needs to be reviewed to allow for many more cases to be finalised.

- Prevention, reaction, and support can be addressed by identifying gaps in the system (additional staff to ensure access when needed such as evenings and weekends).

- Performance targets are damaging the outcome of cases and impact attrition - this policy needs to be revisited by the CJS to better serve victims with the aim of attaining justice.

- Achieving justice, not crime control, must be the driving force in policing.

- Police need to consult with and obtain written permission from past and current partners as part of background checks before granting firearm licenses.

- Improved implementation of the DVA with removal of a firearm - when there is violence firearm licenses must be revoked.

- Information sharing between police, courts, prosecutors, shelters and social workers about gun ownership and threats with a gun.

- Buy-back schemes to reduce number of firearms in the community.

- Statistics on DV must be better kept, not in police/court statistics; and used proactively to prevent crime.

- Since rape impacts on the mental health of victims and increases the risk of long-term psychological consequences, adequate psychosocial support is critical.

- The special sexual offences court must be reinstated its removal is impacting negatively on the outcomes of cases. There is also a need to advocate for legislative intervention.

- Develop a framework to enhance collaboration between NPA and NGOs.

- Improve communication among police, courts, prosecutors' offices, and centres for social work/shelters about data recording, keeping and exchanging about cases of armed domestic violence and perpetrators.

- Draw up a list of best practices to analyse domestic violence and firearms laws and monitor their enforcement.

- An understanding of the implications of choosing one path over another - there will be tradeoffs that require the involvement of other departments.

- A balance across actions to ensure that energy is efficiently dispersed - not fixing the bad while ignoring the good or not investing in adding what is missing. 


\subsection{Child abuse prevalence}

Several child abuse studies were conducted in the Free State (Chandaran, $\mathrm{T}$ ). The first was rapid situational analysis of rape victims registered in hospitals in 2005 and the second was a study to understand the dynamics of interpersonal violence in the province in 2007. The latter was a population-based household survey that looked at the child, partner, elderly and sexual violence separately.

The findings of the studies showed that:

- $30 \%$ of participating children reported abuse - most lived with a parent or grandparent.

- $60 \%$ were female.

- Their mother and father were the main perpetrators.

- Abuse most often occurred at home.

- $22 \%$ experienced abuse daily (battered children).

- Sexual violence happened mostly by strangers.

- Emotional trauma was by far the most severe injury to children (43\%).

- Alcohol and drug use had the most influence on violent behaviors by perpetrators (67\%).

- Children experience heightened anxiety and they fear their parents' response with most expecting to be blamed and punished.

- Older girls act out - becoming aggressive and moody, mixing with the wrong friends, sleeping out, missing school.

\subsubsection{Protecting children from abuse and strengthening parenting}

In 1995 the need for a co-ordinated and integrated response to child abuse, neglect and exploitation was identified and the Department of Social Development was mandated to lead the process of consultation with provincial and national departments as well as welfare organisations and NGOs. A National Committee on Child Abuse and Neglect (NCCAN) was formed and the first strategy drafted the following year. The strategy was reviewed in 2001 and policy revisions made and the Children's Bill, Child Justice Bill and the Sexual Offenses Bill were drafted. The current policy framework and strategy was approved in 2004.

Sexual abuse in children is difficult to diagnose since, despite known sexual activity with children there may not be any physical evidence when a medical examination is performed. Diagnosing sexual abuse in children is therefore based on what has been reported by the child, the perpetrator or an eye-witness. Disclosure by children is a complex process and most likely happens over time, not in a single event. However the wounds of assault can heal within seven days while disclosure may not begin until a few weeks after the event. In addition, disclosure is often delayed because of fear, shame, guilt and pride.

The genital tract is dynamic and its growth and development occurs in three phases or ages: infancy, childhood and adolescence. Oestrogen is critical and has serious effects on the genital tract. An infant maintains oestrogen from its mother from birth to up to three years making the genital tract elastic and able to stretch and appear normal after sexual assault. Adolescent girls develop their own oestrogen by the time they reach puberty.

While sexual assault and abuse is determined by what is told, physical abuse is determined by what one sees and involves pattern, age, and distribution of injuries. Parents must listen carefully to what their children tell them and trust what they are telling them - abuse is not something that a child will fabricate.

The health consequences of child sexual abuse are also well documented and lead to alcohol abuse, depression, HIV and further violent behaviour.

\section{There is insufficient attention paid to the needs of children exposed to violence despite evidence that this can make a real difference.}

\section{- Life orientation curriculum is inconsistently implemented.}

- There is limited psycho-social support in schools, jails and communities at large.

- Current parenting laws reinforce rigid gender roles. 


\subsubsection{The Children's Act, National Policy Framework on Child Abuse, Neglect and Exploitation}

A situational analysis on the fifty state survey conducted by the National Committee on Child Abuse and Neglect (NCCAN) in 1995, concluded that the factors associated with child abuse, neglect and exploitation include, amongst others:

- Socio-political issues;

- Social attitudes towards children;

- Gender roles;

- Poverty;

- Dysfunctional family structures and their functioning;

- Substance abuse;

- Domestic violence;

- HIV and AIDS pandemic;

- Child-headed households;

- Children in care;

- Children with disabilities;

- Children in holding facilities;

- Foreign unaccompanied and undocumented children;

- Traditional and customary practices; and

- Shortcomings in the Child Protection System (CPS).

\subsubsection{Service provision for child rape survivors in KZN}

A service provision audit was conducted for a sample of 200 survivors between October 2004 and December 2006. The audit assessed:

- Medical-Post Exposure Prophylaxis (PEP) (at six months)

- $8 \%$ were HIV-positive.

- $\quad 4 \%$ did not comply with PEP regimens.

- Judicial system (at two years)

- Current services were more effective than first world services in a number of respects (proportion referred for prosecution and proportion found guilty).

- Large number of cases withdrawn by prosecutors.

- Counselling/social work (six months)

- After-hours presentation was associated with reduced likelihood of service provision. There is a need for service 24 hours a day.

- No record of referred cases - there is a need for more effective multi-sectoral monitoring.

\section{Findings of 2007 study on child abuse}

Influence of alcohol and drugs and interpersonal violence

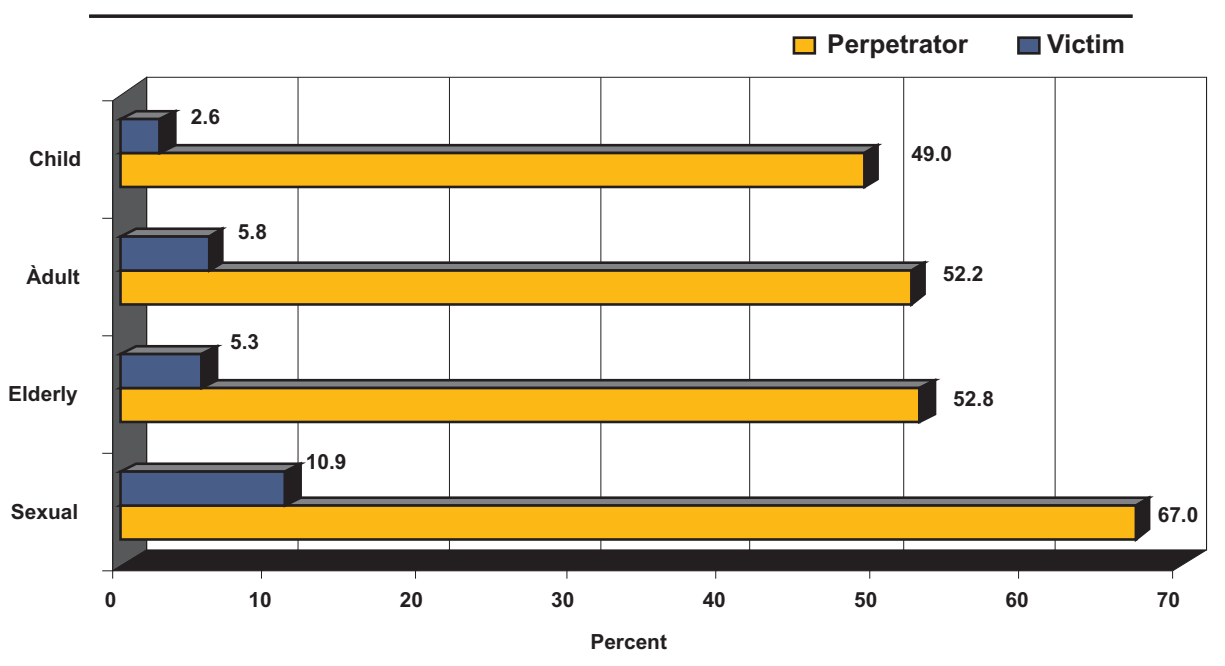





\subsection{Sexual orientation and violence}

There are many contradictions in South Africa related to gender and gender-based violence particularly with regard to lesbian, gay, bisexual, transgender and inter-sex (LGBTI) individuals. Whereas the Universal Declaration of Human Rights protects everyone from violent acts LGBTI are subjected to horrific violence and even murder.

There are currently 20 cases of lesbians who have been raped and murdered in South Africa but only two cases have gone to trial and one of those was postponed 23 times. These crimes were committed by "post-apartheid" generation male youths between the ages of 19 and 24 . Black lesbians have been targeted specifically and three transgender people have been murdered since 1999.

Many attacks on LGBTI individuals are characterised as mere hate crimes when in fact they often occur because of one's sexual orientation, homophobia, or they are attempts at "corrective rape" especially in some townships where lesbian women are raped to make them "straight" again (Eudy case and 777 campaign) and/or the "butch" lesbian is perceived as a threat to patriarchy and masculinity.

Examples include:

- The Noord Street mini-skirt debacle, where a man was arrested for the indecent assault of a woman at a taxi rank, apparently because she was wearing a miniskirt;

- The issue of a woman being stripped naked and paraded through Umlazi in KZN because she defied a ban on wearing pants. The ban was imposed by residents of a nearby hostel. The woman's house was later burnt down;

- The murder of an HIV-positive woman in Khayelitsha because of her status; and

- The xenophobic attacks on cross-border migrants.

It is a sad testimony that only $31 \%$ of domestic violence incidents are reported to the police and $41 \%$ percent of sexual abuse and rape cases were reported. The main reason given by victims for victimisation is homophobia (85\%), while $12 \%$ refused to go for treatment because they feared discrimination.

In 2004, the Joint Working Group (JWG) and UNISA conducted an empowerment study of approximately 500 black and white males and females. The results in the various categories by gender and race are cited below.

\section{A hidden epidemic}

- MSM/WSW are among the most vulnerable minorities, unless they successfully hide.

- They suffer from stigma and discrimination, and are at high risk of losing the safety net from their families.

- This marginalisation increases their disease burden, livelihood loss, destitution, and poverty, and exposes them to an increased risk of loss of life.

Victimisation experienced by black $(n=145)$ and white $(n=50)$ females over 24 months (2002 and 2003)

\begin{tabular}{|l|l|l|}
\hline & Black & White \\
\hline Verbal abuse & $36.1 \%$ & $40 \%$ \\
\hline Domestic violence & $17.2 \%$ & $8.2 \%$ \\
\hline Physical abuse/Assault & $15 \%$ & $16 \%$ \\
\hline Attacks on property/possessions & $12.6 \%$ & $15.4 \%$ \\
\hline Sexual Abuse/Rape & $9.7 \%$ & $4 \%$ \\
\hline
\end{tabular}

Victimisation experienced by black $(n=141)$ and white ( $n=116)$ males (gay men) over 24 months (2002 and 2003)

\begin{tabular}{|l|l|l|}
\hline & Black & White \\
\hline Verbal abuse & $38.9 \%$ & $32.8 \%$ \\
\hline Domestic violence & $7.8 \%$ & $6.9 \%$ \\
\hline Physical abuse/Assault & $15.4 \%$ & $14.7 \%$ \\
\hline Attacks on property/possessions & $15.6 \%$ & $16.4 \%$ \\
\hline Sexual Abuse/Rape & $9.4 \%$ & $5.2 \%$ \\
\hline
\end{tabular}




\subsubsection{HIV prevalence and links}

Contrary to the belief that lesbian women are relatively risk-free from HIV, the following statistics reflect the prevalence of lesbian women and gay men tested for HIV. It should be noted that some lesbians could have bi-sexual partners and/or experience high levels of rape.

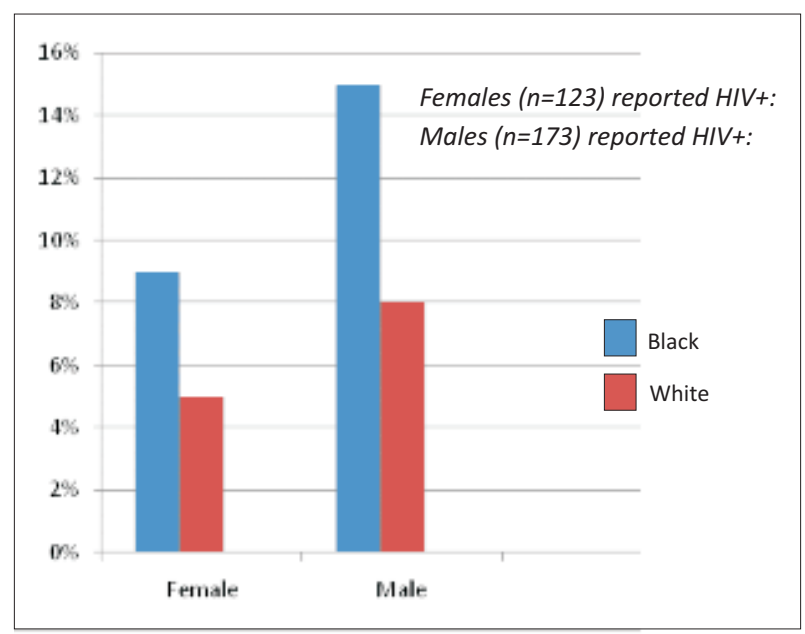

\section{The HIV/AIDS bridges between MSM/WSW and the general population}

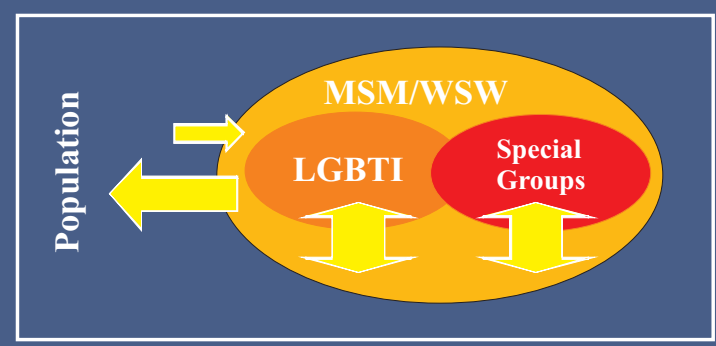

Risk of being subject to violence due to sexual orientation

$\square \quad$ Non - existent

$\square$ Medium

$\square$ High

$\square$ Very High

MSM: Men who have sex with men

WSW: Women who have sex with women

LGBTI: Lesbian, Gay, Bisexual, Transgender and Intersex people Special Groups: eg. Inmates of correctional institutions

$\longrightarrow$ Spillover of HIV and AIDS

\subsubsection{Recommendations}

- Recognise LGBT people as a vulnerable group and provide funding for sensitisation training to the SAPS victim's support counsellors.

- A complete unpacking of the term gender and inclusion of the term "genders" which encompasses more than males/females - multiple orientations such as transgender and intersex individuals; Include gender identity in the analysis, the messages and response.

- Address the challenge of language - political leaders need to be held accountable for the language they use.

- Work on masculinity also needs to include homophobia. Violence can be reduced if tolerance is increased and through programmes to reach men who have sex with men (MSM) and women who have sex with women (WSW); reduce secrecy/ increase tolerance.

- Focus on the dysfunction of the justice system - very qualified prosecutors are involved in the two trials (out of the 20 cases) yet they fail to see that transgressing gender roles contributed to the murders.

- Address the issue of patriarchy in media, religion, state - government needs to speak out and develop policy interventions as well as ensure that current legislation is implemented; and Collaboration between government (prevention messages); NGOs/civil society (spread the messages and human rights) and LGBTI associations (care, treatment, livelihood support).

- Large-scale HIV prevention programmes should include various target groups and all provinces and should not be limited to one city or one target group.

- Training to debunk myths and stereotypes of gender, gender identity and sexual practices (behaviour and meaning) to lessen homophobia and increase tolerance.

- Changing social norms is important and must be done on a massive scale with community involvement and include mass media, community involvement, education and training. 


\subsection{Responses from prevention partners and government}

Local and international partner organisations of the Population Council and AED shared their gender-based violence projects and lessons learned.

\subsubsection{Lessons learned in the health sector}

Health workers and the health sector must get involved in domestic violence because of:

- Prevalence rates.

- Health consequences.

- Opportunities to address such violence.

- The ethical and moral responsibility of individuals to play a role.

Numerous opportunities exist for the health sector to provide care to SGBV survivors. Based on the number of people attending health facilities, health workers are often the first point of contact. Some victims or survivors presenting at health facilities will disclose that they've been violated, while others may not disclose this, but may have symptoms. Early identification could help with treatment, limit the consequences and decrease further violence.

Many health workers know little about how to manage SGBV clients and scant attention is paid to DV. Yet there are many ways in which the health sector can be strengthened to deal with the issue:

- Identify appropriate medical and counselling services

- Make health services available at first point of contact - Referrals for other services

- Integration of various medical services.

- Capacity of health workers to screen routinely.

- Capacity of health workers to diagnose accurately especially for children.

- Clarify and enable legal requirements for reporting an assault - or suspicion of an assault.

- Role of forensic evidence in prosecution.

\section{Package of comprehensive sexual}

\section{assault care by healthcare workers for}

\section{rape victims}

- Document pertinent history.

- Perform a thorough physical examination.

- Collect legal evidence.

- Screen for STI and HIV.

- Treat physical injuries.

- Prevent unwanted pregnancy.

- Prevent and treat STIs.

- Provide post exposure prophylaxis for HIV.

- Provide psychological support.

- Refer to appropriate resources.

- Present evidence in court. 


\subsubsection{Achievements in the health sector response to rape in South Africa}

Sexual Assault Services are the most excluded clinical legal services. These services were initially addressed within the District Surgeon System. This was changed to a District Medical Officer System that was integrated into primary health care services. Subsequently separate Sexual Assault Services were provided that included:

- Most excluded other clinical medico-legal services.

- Some provide ex officio services.

- Introduction of PEP for victims of sexual assault (2002).

Administrative level interventions currently provide the following:

- A national level unit deals with sexual assault services.

- Most provinces established units responsible solely for this service (Gauteng, Free State, Northern Cape, KwaZulu-Natal).

- Others still have service integrated with other programmes (Mental Health, etc).

- All provinces are now expected to designate facilities (Criminal Law (Sexual Offences and Related Matters) Amendment Act, 2007).

- A training programme has been designed (Sexual Assault Management and Care).

- Use of forensic nurses/sexual assault care practitioners in most provinces.

Although much more needs to be done, including more research, some emerging approaches are:

- One-stop integrated medico-legal centre

- Thuthuzela Care Centres, Uganda, Zambia

- Integrated, comprehensive health services with structured referrals for legal services

- Refentse, Ethiopian Society of Obstetrics Gynaecology, Kenya MOH/Liverpool VCT, Nairobi Women's Hospital

- Help desks at clinics

- Thohoyandou Victim Empowerment Programme,

\section{- Strengthening police responses}

- Copperbelt Model of Integrated Care

- Establishing bi-directional linkages between police and health facilities

- Thohoyandou Victim Empowerment Programme, Liverpool VCT

\subsubsection{Recommendations}

- Community awareness to generate demand for services.

- Involvement of strategic and most vulnerable communities.

- Empower vulnerable communities.

- Involvement of Government and relevant partners in all activities.

- SGBV services available nationally.

- Core services at the service centres and people who actually own the services with departments and health facilities.

- Controlled Integration with other service providers

- Special area - auditory and visual privacy

- Vulnerability of victims

- Dedicated full-time staff

- Recognition of sexual assault service as a specialty.

- Service Excellence Centres

- Research, training, quality care, outreach

- Established referral networks

- Number dependent on need, population and geographic size.

- Direct linkages with other stakeholders.

- Dedicated personnel: identify, recognition, reward, involve, engage, ownership.

- Strong collaboration to respond to the needs and ensure comprehensive care is available.

There is no blueprint of sexual assault services, however the model used must be adaptable to local settings, must be evidence-based and encourage inter-sectoral collaboration. 


\section{CONCLUSION}

South Africa faces an overwhelming problem of genderbased violence. Not only is this a violation of human rights of women and girls, it is also a major cause of mortality and morbidity.

SGBV is a key driver of the HIV epidemic for women. For men, the constructions of masculinity which are predicated on gender hierarchy and valourise toughness and risk taking are a key driver of SGBV as well as HIV.

\section{"Effective prevention of}

\section{SGBV requires a}

\section{comprehensive cross-}

\section{sectoral approach with}

\section{buy-in and political}

\section{support at all levels of}

\section{government. No single}

\section{strategy will do the job."}

Effective prevention of SGBV requires a comprehensive cross-sectoral approach with buy-in and political support at all levels of government. No single strategy will do the job. At present, there is insufficient co-ordination and engagement to effectively implement the national 365-day plan. There has also been limited engagement with civil society and oversight mechanisms like the CGE and ICD face challenges. For any prevention interventions to work, civil society must work closely with government and increase its capacity to engage in policy, advocacy and community mobilisation. Similarly, public sector capacity must be strengthened. Lastly, the involvement of traditional and religious leaders cannot be overlooked.

While specific recommendations have been made per sector there are general recommendations which apply across-the board and which will require cross-sectoral collaboration and commitment.
- Real commitment between and a concerted effort by civil society and government.

- Increase civil society's capacity to engage in policy, advocacy and community mobilisation.

- Strengthen public sector capacity.

- Involvement of traditional and religious leader.

- Involvement of state institutions, political parties, social movements, other organs of society.

- An accountability and management role is needed but it is not clear who will take the lead.

- Reduce poverty.

- Change constructions of masculinity to those that are more gender equitable.

- Strengthen family values.

- Reduce exposure to violence in childhood.

- Reduce levels of alcohol consumption and enforce alcohol laws.

- Ensure stricter gun control.

- Institute comprehensive, broad-based social norms campaigns that build on positive policies such as gun control.

It is hoped that the findings presented at the symposium will inspire stakeholders across all sectors to join forces to formulate a plan of action; that the symposium will guide advocacy and inform future interventions and research needs towards comprehensive HIV prevention in South Africa.

For more detail on the presentations made at the symposium, go to www.popcouncil.org. 


\section{APPENDICES}

\section{Prevention interventions that have worked in South Africa}

\section{Stepping Stones Study}

The Stepping Stones study was a gender-transformative programme for HIV prevention that aimed to improve sexual health through building stronger and more gender equitable relationships. It has been used in 100 settings around the world and is a comprehensive approach to prevention that uses participatory methods, critical reflections and skills building.

The model was adapted for South Africa from Uganda in 1998 and implemented in 64 rural villages and six townships in Umtata in the Eastern Cape. A total of 2800 young men and women were interviewed, tested for HIV and herpes at baseline, and followed for two years after being involved in Stepping Stones.

Stepping Stones found that men in the programme after two years:

- Had a 33\% reduction in new infections of herpes compared with those who were not in programme;

- Were $1 / 3$ less likely to have acquired herpes;

- Were $38 \%$ less likely to have perpetrated physical and sexual intimate partner violence This has been sustained two years after the intervention

After one year the men who went through Stepping Stones had:

- Fewer partners;

- Fewer problems with alcohol; and

- Less transactional sex.

By applying a gender transformative intervention, risktaking and violent anti-social construction astransformed. The study showed that you can reduce men' sexul risk, the cquisition of sexual infections, he erpetration of violence and reduce other risk factors and forms of risk-taking.

"Impact of Stepping Stones on the incidence of HIV and HSV-2 and sexual behaviour in rural South Africa: cluster randomised controlled trial."

Rachel Jewkes, M Nduna, J Levin, N Jama, K Dunkle, A Puren, and N Duvvury, BMJ. 2008337: a506. Published online 2008 August 7. doi: 10.1136/bmj.a506.

PMCID: PMC2505093

\section{IMAGE Study}

IMAGE was a cluster randomized trial that was initially conducted between 2001-2004 combining microfinance with gender and HIV training. The research raised he question: Can IMAGE empower women and reduce intimate partner violence?

The IMAGE programme was delivered by the Small Enterprise Foundation that provided the loans to poorest women in the villages under the study. To date there are 54923 clients and twice weekly loan repayment meetings are held. During the loan repayment sessions, one-hour ender and HIV sessions take place that focus on gender norms, domestic violence, sexuality, HIV and AIDS, and communication skills.

Another component of the gender/HIV training involves community mobilisation through the Sisters for Life programme which takes the lessons learned in the training and begins engaging men and youth in communities.

One woman stated: "I used to be very poor. I cleaned other people's houses, I was forced to beg for food... Now I feel like a madam, I can pay my children's school fees and at night I sleep with the light where before I watched the light in the other houses.

Results of the study showed that after two years, the risk of physical and sexual violence in the preceding year was reduced by $55 \%$.

- Shifts in attitudes towards violence.

- More confidence to leave abusive relationships.

- Reduced conflicts over finances.

- Women spoke openly in meetings about abuse

- Women confronted members who contributed to other women's abuse or witnessed abuse of other women.

- Women provided solidarity and support to other women leaving violent relationships.

"Understanding the Impact of a Microfinance-Based Intervention on Women' Empowerment and the Reduction of Intimate Partner Violence in South Africa"

Julia C. Kim, Charlotte H. Watts, James R. Hargreaves, Luceth X. Ndhlovu, Godfrey Phetla, Linda A. Morison, Joanna Busza, John D.H. Porter, and Paul Pronyk Am J Public Health. 2007 October97(10): 1794-802. doi: 10.2105/AJPH.2006.095521.

PMCID: PMC1994170 

